\title{
Involvement of MEK, ERK, PKC $\zeta$ and GSK3 $\beta$ in Maintaining the Mitotic Spindle
}

\author{
Madhavi Kalive $^{1} \&$ David G. Capco ${ }^{1}$ \\ ${ }^{1}$ School of Life Sciences, Cell and Molecular Biosciences, Arizona State University, Tempe, AZ, USA \\ Correspondence: David G. Capco, School of Life Sciences, Cell and Molecular Biosciences, P. O. Box 874501, \\ Arizona State University, Tempe, AZ 85287-4501. Tel: 1-480-965-7011. E-mail: dcapco@asu.edu
}

Received: December 21, 2012 Accepted: February 1, 2013 Online Published: February 28, 2013

doi:10.5539/ijb.v5n2p1 URL: http://dx.doi.org/10.5539/ijb.v5n2p1

\begin{abstract}
The MAPK pathway has been implicated in various functions related to cell cycle regulation. MAPKK (MEK) is part of this pathway and the extracellular regulated kinase (ERK) is its known downstream target. Glycogen synthase kinase $3 \beta$ (GSK3 $\beta$ ) and protein kinase $\mathrm{C} \zeta(\mathrm{PKC} \zeta)$ also have been implicated in cell cycle regulation due to their association with the centrosomes along with MEK and ERK. In the current study, we tested the effects of inhibiting MEK on the activities of ERK, GSK3 $\beta, \mathrm{PKC} \zeta$, and $\alpha$-tubulin. Two types of MEK inhibitors were used, a siRNA inhibitor and U0126. The effects of MEK inhibition were tested by immunocytochemistry and confocal analysis, western blotting, RT-PCR analysis and study of cell numbers in M-phase stages. Results from this study indicate that inhibition of MEKdid not inhibit GSK3 $\beta$ and PKC $\zeta$ enrichment at the centrosomes. However, the mitotic spindle showed a reduction in the pixel intensity of microtubules and also a reduction in the number of cells in each of the M-phase stages. A peptide activation inhibitor of ERK was used next. Our results indicated a further decrease in mitotic spindle microtubules than what was seen with the MEK inhibitors and an absence of cells in most of the M-phase stages. GSK3 $\beta$ and PKC $\zeta$ enrichment were however not inhibited at the centrosomes. Taken together, the kinases GSK3 $\beta$ and PKC $\zeta$ may not function as a part of the MAPK pathway to regulate the mitotic spindle.
\end{abstract}

Keywords: PKC, GSK, MAPK, mitotic spindle, centrosome

\section{Introduction}

The MAPK pathway is involved in a multitude of functions including cell cycle regulation, cell differentiation, and cell death in eukaryotes ranging from yeast to humans (Nigg et al., 2001; Orton et al., 2005; Rozengurt, 2007; Marks et al., 2009). As part of this pathway, many somatic cell studies have shown that Raf kinase activates MEK1/2 (MEK) by phosphorylation of two serine residues. MEKs generally recognize only specific MAPKs as substrates. It has been reported that MEK phosphorylates ERK 1/2 (ERK) at threonine and tyrosine residues in a 'TEY' motif within its activation loop (Yung et al., 1997, Orton et al., 2005).

In mammalian mitosis, the MAPK pathway in has been extensively examined. For example studies indicate that activation of the MEK/ERK pathway is required for normal progression into mitosis (Guadagno \& Ferrell, 1998; Wright et al., 1999; Hayne et al., 2000). In somatic cells such as the 3 T3 cells used in this study, the mitotic spindle is centrosomal and a dynamic structure that facilitates chromosome segregation. Many studies have observed that the mitotic spindle apparatus is composed of several elements including centrosomes, microtubules such as astral, polar, and kinetochore microtubules, kinetochores of chromosomes, and associated proteins (McIntosh \& Landis, 1971; Burbank et al., 2007; Walczak \& Heald, 2008; Schmidt et al., 2010). It has been reported that activated MEK and ERK localize to the centrosomes of the mitotic spindle from prophase to anaphase, and to the midbody during cytokinesis (Shapiro et al., 1998; Willard \& Crouch, 2001; Collelo et al., 2012). ERK, the known downstream target of MEK has been shown to be associated with the centrosome and kinetochore components of the mitotic spindle apparatus, and has multiple functions during mitosis including, promoting mitotic entry as well as targeting proteins that mediate mitotic progression in response to kinetochore attachment (Schmidt-Alliana et al., 1998; Shapiro et al., 1998; Saffery et al., 2000). Activated ERK co-localizes with the kinetochore motor protein CENP-E, raising the possibility that CENP-E is a downstream effector for ERK during mitosis (Zecevic et al., 1998; Willard \& Crouch, 2001; Chambard et al., 2006). Studies have shown that blocking MEK activity in cycling somatic cells does not significantly affect mitotic entry, but it does slow 
progression through mitosis, probably by slowing the CENP-E-dependent chromosome movements coordinated by the mitotic spindle (Roberts et al., 2002). Other studies have shown that active MEK along with active cyclinB-Cdc2 is necessary for the cells to progress into M-phase (Harding et al., 2003; Walsh et al., 2003).

Signaling networks are important for cell proliferation, and communication between pathways can take place at many locations from the plasma membrane to the nucleus. MAPK pathways cross-communicate with other signaling pathways such as the GSK3 pathway and the PKC pathway (Nigg, 2001; Zhang \& Liu, 2002; Kholodenko, 2006; Rozengurt, 2007). Glycogen synthase kinase $3 \beta$ (GSK3 $\beta$ ) and protein kinase C (PKC) have been found to be associated with the mitotic spindle (Lehrich \& Forrest, 1994; Etienne-Manneville \& Hall, 2003; Wakefield et al., 2003; Jope \& Johnson, 2004; Liu et al., 2006; Kalive et al., 2011). Earlier studies have shown that GSK3 $\beta$ is associated with the centrosome and is known to phosphorylate microtubule associated proteins (MAPs) such as MAP1B which in turn causes chromosomal segregation by the microtubules. In these studies the MAPK pathway was shown to be upstream of GSK3 $\beta$ (Goold et al., 1999; Frame \& Cohen, 2001; Goold et al., 2005; Scales et al., 2009).

PKCs also have been reported previously as upstream activators of the MEK/ERK pathway (Brändlin et al., 2002; Puente et al., 2006; Chang et al., 2008; Marks et al., 2009). In an earlier study the PKC $\zeta$ isoform has been implicated to be an upstream activator of MEK (Berra et al., 1995; Short et al., 2006). In addition, the PKCל isoform has been shown to be associated with the centrosome region of the mitotic spindle, or with the spindle microtubules (Lehrich \& Forrest, 1994; Liu et al., 2006), and its activation is known to play an important role in stable kinetochore-microtubule attachment and subsequent chromosomal separation (Liu et al., 2006). PKC isoforms can directly regulate Raf-1 which is an upstream activator of the MEK/ERK pathway, specifically PKC $\alpha$ and PKC $\eta$ are known activators of Raf-1 (Schonwasser et al., 1998; Corbit et al., 2003). A previous study showed that inhibition of active PKC $\zeta$ by a myristoylated peptide inhibitor causes an inhibition of p(ser9)GSK3 $\beta$ at the centrosomes and causes a disruption of the mitotic spindle. This study also suggests that $\mathrm{p}(\operatorname{ser} 9)$ GSK3 $\beta$ could be a substrate of active PKC $\zeta$ (Kalive et al., 2011). However, no single study has examined all four of the kinases at the same time in the same cell type.

Taken together these studies indicate that MEK, ERK, PKC $\zeta$, and GSK3 $\beta$ can all be important kinases involved with the mitotic spindle and its regulation. However from these previous studies it is not clear if these kinases are part of a single signaling pathway that regulate the mitotic spindle apparatus or whether there are multiple pathways engaged in cross-talk between the pathways.

In this study, MEK and ERK activity were separately inhibited in the same cell type and it was determined whether this inhibition affects the location and activity of PKC $\zeta$ and GSK3 $\beta$. If MEK/ERK, PKC $\zeta$, and GSK3 $\beta$ interact then we predicted that they would co-localize at the spindle during mitosis. Moreover, if MEK and ERK have sole control over the mitotic spindle then inactivation of either MEK or ERK may obliterate the spindle and progression through mitosis. In contrast, if multiple signaling pathways are involved then a modification or reduction in the spindle might be observed and only a reduction in the progression through mitosis.

\section{Materials and Methods}

\subsection{Cell Culture and Media}

Mouse fibroblasts or NIH 3 T3 cells (ATCC number CRL-2795) were used for all the experiments. The cells were maintained in Dulbecco's Modified Eagle's Medium (DMEM) (10\% calf serum, $1 \%$ penicillin-streptomycin, $2 \% \mathrm{~L}$-glutamine). A $37^{\circ} \mathrm{C}$ moisture incubator at a $10 \% \mathrm{CO}_{2}$ concentration was used for the cells and the cells were grown to $80 \%$ confluency before being used. All chemicals used in experiments were obtained from Sigma (St. Louis, MO USA) unless otherwise indicated.

\subsection{Inhibitor Treatment: MEK siRNA, U0126, ERK activation Peptide Inhibitor}

The inhibitor concentration and the inhibitor exposure time were determined by a dose-response analysis.

MEK siRNA: 3T3 cells were exposed to increasing concentrations of the inhibitor according to the protocol provided by the manufacturer (Santa Cruz Biotechnology, Santa Cruz, CA USA). Briefly, MEK siRNA at concentrations of $1 \mu \mathrm{M}, 5 \mu \mathrm{M}, 10 \mu \mathrm{M}$, and $20 \mu \mathrm{M}$ were introduced into cells using the reagents supplied by the manufacturer. After $48 \mathrm{hrs}$ cells were subjected to immunocytochemicalanalysis using the pMEK specific antibody, and then viewed by confocal microscopy. The optimal concentration of the MEK siRNA inhibitor i.e. the lowest possible concentration that completelysuppressed pMEK was determined as $10 \mu \mathrm{M}$ and was used at this concentration for the studies performed.

U0126 inhibitor: 3T3 cells were exposed to increasing concentrations of the inhibitor (Calbiochem, La Jolla, CA USA) at $10 \mu \mathrm{M}, 25 \mu \mathrm{M}, 100 \mu \mathrm{M}$, and $150 \mu \mathrm{M}$ in DMEM media for $5.5 \mathrm{~h}$, then subjected to 
immunocytochemical analysis using thepMEKspecific antibodyand viewed by confocal microscopy. The optimal concentration of the inhibitor wasdetermined as $100 \mu \mathrm{M}$ which was the lowest possible concentration that completelysuppressed pMEK. MEK inhibitor U0126 was used at $100 \mu \mathrm{M}$ for $5.5 \mathrm{~h}$ for the studies performed.

ERKactivation peptide inhibitor: 3T3 cells were exposed to increasing concentrations of the peptide inhibitor (Calbiochem, La Jolla, CA USA) such as $10 \mu \mathrm{M}, 25 \mu \mathrm{M}, 100 \mu \mathrm{M}$, and $150 \mu \mathrm{M}$ in DMEM media for $4 \mathrm{~h}$, then subjected to immunocytochemical analysis using thepERKspecific antibody and viewed by confocal microscopy. The optimal concentration of the inhibitor was determined as $100 \mu \mathrm{M}$ which was the lowest possible concentration that completely suppressed pERK. ERK inhibitor was used at $100 \mu \mathrm{M}$ for $4 \mathrm{~h}$ for the studies performed.

\subsection{Immunocytochemistry}

In order to perform the immunocytochemical analysis, the living $3 \mathrm{~T} 3$ cells were first fixed intact for $30 \mathrm{~min}$ in $2 \%$ formaldehyde in ICB (ICB-100 mM KCl, $5 \mathrm{mM} \mathrm{MgCl}_{2}, 3 \mathrm{mM}$ EGTA, and $20 \mathrm{mM}$ HEPES (pH 6.8), in $\mathrm{H} 2 \mathrm{O}$ ). Permeabilization of the cells was performed next; this was done for $1 \mathrm{~h}$ in ICB with $2 \%$ paraformaldehyde and $1 \%$ Tween-20. Before the addition of primary antibodies, the cell samples were washed three times for 15 min each wash using ICB-bovine serum albumin (BSA) buffer (1\% BSA in ICB). An antibody dilution buffer ( $1 \%$ nonfat milk, $0.5 \%$ Tween-20 in ICB) was used at a 1:500 dilution for each primary antibody added. Primary antibodies were added as separate experiments. The primary antibodies used were: anti-pMEK, anti-tMEK,

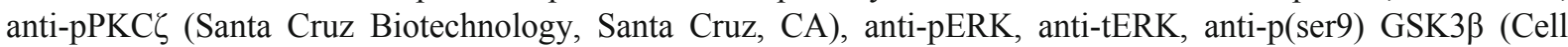
Signaling Technology, Beverly, MA USA), anti- $\alpha$-tubulin (Sigma Aldrich, St. Louis, MO USA), anti- $\gamma$-tubulin (Sigma Aldrich, St. Louis, MO USA). In each experiment primary antibody was added to the cell samples overnight at $4^{\circ} \mathrm{C}$ on a gentle rocker. A 1:1000 dilution of each corresponding secondary antibody was prepared in the antibody dilution buffer and the secondary antibodies were also added overnight at $4^{\circ} \mathrm{C}$ on a gentle rocker. The secondary antibodies used were Alexa-568- and Alexa-488-conjugated IgGs (Molecular Probes Inc, Eugene, OR USA). Following the addition of the secondary antibody, the cell samples were washed with the ICB-BSA buffer three times, 15 min each wash. This was followed by a 15 min incubation of the samples in DRAQ5 (2.4 $\mu \mathrm{g} / \mathrm{mL}$ in ICB [AXXORA, LLC]) to visualize the chromosomes by confocal microscopy. All experiments were performed in triplicate independently.

\subsection{Confocal Microscopy}

After performing the immunocytochemistry procedure, a Leica SP2 microscope was used to view the cells. This microscope was housed in the W. M Keck Bioimaging Laboratory at Arizona State University. A 100x oil objective was used and multiple lasers (argon $488 \mathrm{~nm}$; krypton $568 \mathrm{~nm}$ ) were used for simultaneous imaging of the Alexa 488 and Alexa 568 flouorophore-labeled samples. Images were scanned as $0.5 \mu \mathrm{M}$ slices in the Z-axis at the spindle region. Leica NTS software (Leica Microsystems, Bannockburn, IL USA) was used to amalyze the images.

\subsection{Cell Cycle Quantification}

3 T3 cells were treated with MEK siRNA, U0126, ERK activation peptide inhibitor or left untreated as control cells in separate experiments. After performing the immunocytochemistry procedure, cells were labeled with an antibody against $\alpha$-tubulin. The chromosomes were visualized by staining with DRAQ1 $(2.4 \mu \mathrm{g} / \mathrm{mL}$ in ICB [AXXORA, LLC]). The cells viewed by confocal microscope were divided into quadrants and a total of about four thousand cells were analyzed. The number of cells in the cell cycle stages such as, pre-metaphase (stages earlier than metaphase), metaphase, anaphase, telophase, and cytokinesis were counted within each of the quadrants. This was repeated for all the treatments studied. Every treatment experiment was performed in triplicate, the numbers of cells in each cell cycle stage were counted, an average calculated along with the standard error of the mean and the averages were converted to percentages. This data was then represented graphically with the cell cycle stages on the X-axis and the percentage numbers of cells in each cell cycle stage on the Y-axis. Statistical significance was calculated by comparing the control values versus experimental values using a Student t-test and a probability of $\mathrm{p}<0.05$ was considered as significant. All experiments were performed in triplicate independently.

\subsection{Transfection with MEK Plasmid}

MEK plasmid was transiently transfected into $3 \mathrm{~T} 3$ cells according to the protocol by Life technologies Inc. using Lipofectamine $^{\mathrm{TM}} 2000$ (Life technologiesInc, Carlsbad, CA USA). Briefly, cells were grown in $60 \mathrm{~mm}$ petri-dishes until $70 \%$ confluent. Twenty-four hours after transfection fresh media was added to the cells and 
after 48 hof transfection cells were used for further analyses. The same protocol was followed when cells were transiently transfected with a combination of MEK plasmid and MEK siRNA.

\subsection{RNA Isolation and RT-PCR}

$3 \mathrm{~T} 3$ cells were grown in $60 \mathrm{~mm}$ petri-dishes until they were $70 \%$ confluent. The total RNA from each of the petri-dishes was isolated after $48 \mathrm{hrs}$ of treatment, and then reverse transcriptase (RT) reaction was conducted to isolate the cDNA from each treatment category. RNA easy mini kit (Qiagen, Maryland USA) was used to isolate the RNA. The isolated cDNA was then subjected to PCR (polymerase chain reaction). The primers used for the PCR reactions were, forward and reverse primers for MEK (Santa Cruz Biotechnology, CA) and the forward and reverse primers for GAPDH (glyceraldehyde 3-phosphate dehydrogenase) (Santa Cruz biotechnology). The RT-PCR products were run on a $1 \%$ agarose gel along with the $1 \mathrm{~kb}$ DNA ladder as a molecular weight marker.All experiments were performed in triplicate independently.

\subsection{Immunoblotting}

The experimental samples were subjected to SDS-PAGE analysis. A Laemmli $2 \times$ sample buffer was added to the samples (Laemmli, 1970), then the samples were placed in a boiling water bath for $10 \mathrm{~min}$ to denature the proteins. Samples were loaded onto a pre-cast $10 \%$ Tris- $\mathrm{HCl}$ precise protein gel (Pierce Biotechnology, Rockford, IL USA) at a concentration $750 \mu \mathrm{g} / \mathrm{ml}$ in each lane. A Bradford protein assay was performed in order to determine the concentration of protein that was loaded onto the SDS gel. The Kaleidoscope protein dye was used as the marker to confirm molecular weight. A PVDF membrane (Towbin et al., 1979) was used to transfer the protein gel. The blot was blocked in BLOTTO (5\% percent non-fat dried milk in PBS-T [PBS with 0.1\% Tween-20]) for $1 \mathrm{~h}$, before using primary antibodies. A 1:500 dilution of the appropriate primary antibody was applied to the blot overnight at $4^{\circ} \mathrm{C}$. The appropriate horseradish peroxidase (HRP) conjugated secondary antibody (Pierce Biotechnology, Rockford, IL USA) was applied to the blot after washing the blot with PBS-T three times. Secondary antibodies were diluted 1:1000 in BLOTTO and applied to the blot for $2 \mathrm{~h}$ at room temperature. To detect the protein bands on the blot, the ECL plus kit (formerly Amersham Biosciences, Arlington, IL) and the Hyperfilm ECL chemiluminescent film (GE Healthcare, Arlington, IL) were used. The protein bands from the blots were quantified by calculating the average pixel intensities of the each protein band from three independent experiments and plotting them as a histogram. Image J software was used to calculate the relative band intensity of the protein bands. Statistical significance was calculated by comparing the control values versus experimental values using a Student t-test and a probability of $\mathrm{p}<0.05$ was considered as significant.

\section{Results}

\subsection{Effects of Inhibitors of MEK on the co-Localization of $p M E K$ with $p P K C \zeta$ and with $p(\operatorname{ser} 9) G S K 3 \beta$}

The effects of MEK inhibitors on the co-localization of pMEK with pPKC $\zeta$ and $\mathrm{p}(\operatorname{ser} 9) \mathrm{GSK} 3 \beta$ atthe metaphase stage of $3 \mathrm{~T} 3$ cells were tested with 2 types of treatmentscompared to the control cells (no treatment). The treatments appliedin parallel were: 1) Cells treated with the MEK small inhibitor RNA (MEKsiRNA); and 2) Cells treated with the MEK chemical inhibitor, U0126. The concentration of MEK siRNA and U0126, and the duration of exposure were determined using a dose response analysis (see Materials and Methods).All the cells in culture dishes analyzed were in metaphase. In all figures, the chromosomes can be visualized as blue as a result of labeling with DRAQ5.In control cells(Figures 1a, b, and c), the enrichment of pMEK and p(ser9)GSK3 $\beta$ was assessedby labeling the cells both with a pMEK specific antibody (binds to active MEK) and $\mathrm{p}(\mathrm{ser} 9)$ GSK $3 \beta$ specific antibody (binds to inactive (ser9)GSK3 $\beta$ ). The enrichment of pMEKwas visualized as red in the centrosomal areas on either end of the metaphase plate (indicated by arrows in Figure 1a), and the enrichment of $p(\operatorname{ser} 9)$ GSK3 $\beta$ was visualized as green in the centrosomal areas on either end of the metaphase plate in Figure 1b, thus co-localization between the two appearsas yellow spots at the centrosomal areas on either end of the metaphase plate, in the merged image in Figure 1c. In order to confirm that the spots on either end of the metaphase plate chromosomes were centrosomes, cells were co-labeled with a centrosomal marker, $\gamma$-tubulin (Habermann \& Lange, 2012), along with pMEK. The inset in Figure 1c indicates a representative metaphase cell co-labeled with antibodies to pMEK (red) and $\gamma$-tubulin (green) so that the co-localization at the centrosomes is visualized as yellow. In earlier studies, $\mathrm{pPKC} \zeta$ has been shown to be localized to the centrosomes of the mitotic spindle (Lehrich \& Forrest, 1994; Liu et al., 2006). To test if pPKC $\zeta$ co-localized with pMEK, the enrichment of pMEK and pPKC $\zeta$ was assessed next in control cells by labeling the cells with a pMEK specific antibody (red) and $\mathrm{pPKC} \zeta$ specific antibody (green) (Figures 1d, e, and f). Co-localization between the two appears yellow at the centrosomal areas in the merged image in Figure 1f. 


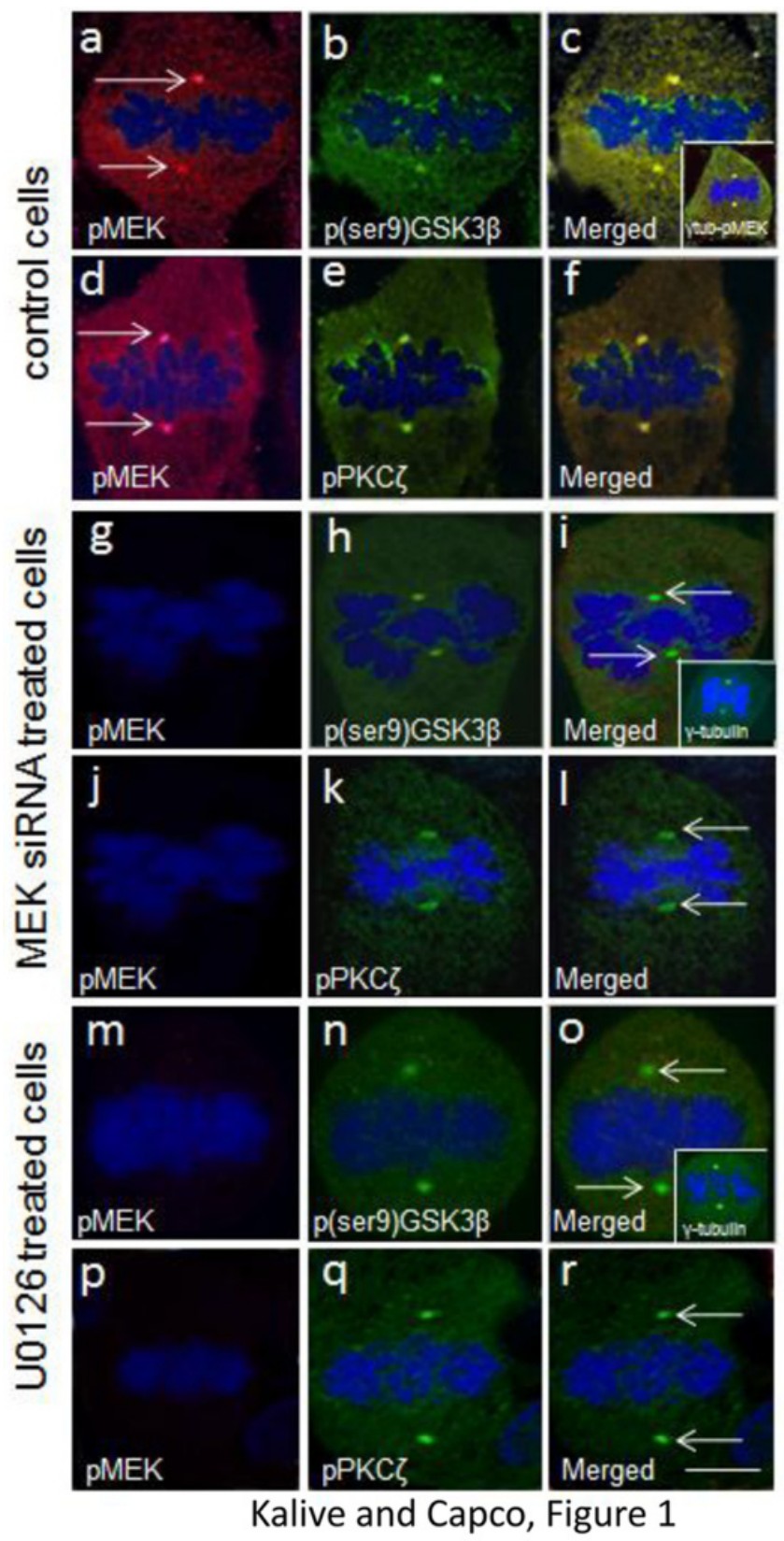

Figure 1. Effect of MEK inhibition on the co-localization of pMEK with p(ser9)GSK3 $\beta$ and pPKC $\zeta$ in $3 T 3$ cells (a) In control cells pMEK (red) was tested for co-localization with (b) p(ser9)GSK3 $\beta$ (green) by immunocytochemistry and confocal microscopy. (c) The co-localization of pMEK and p(ser9)GSK3 $\beta$ can be visualized in a merged image with the co-localized areas showing yellow pixels. The arrows in (a) indicate the enrichment of pMEK at the centrosome regions. The inset in (c) is a merged image of a control cell to show the co-localization of pMEK and $\gamma$-tubulin at the centrosomes. (d) In control cells pMEK (red) was tested for co-localization with (e) pPKC $\zeta$ (green) and in the merged image (f) is yellow. (g) In MEK siRNA treated cells, pMEK is absent and there is no co-localization with (h) p(ser9)GSK3 $\beta$ (green). Thus (i) in the merged image the centrosomes are green since there is no co-localization. The arrows in (i) indicate the green pixels at the centrosomes. The inset in (i) is an image of a MEK siRNA treated cell that shows the enrichment of $\gamma$-tubulin at the centrosomes. (j) In MEK siRNA treated cells, pMEK (red) is absent, while (k) pPKC (green) is present. Thus (l) in the merged image the centrosomes are green since there is no co-localization and this is indicated by arrows. (m,n) In U0126 treated cells, there is an absence of pMEK (red) while p(ser9)GSK3 $\beta$ (green) is present. In the merged image (o) there are green pixels at the centrosomes indicated by arrows. The inset in (o) shows $\gamma$-tubulin at the centrosomes. (p, q) In U0126 treated cells, there is an absence of pMEK (red) while pPKC $\zeta$ (green) is present. In the merged image (r) centrosomes are green indicated by arrows. All experiments were performed in triplicate. Scale bar is $10 \mu \mathrm{m}$. 
In cells treated with the MEK siRNA, the effects of inhibiting MEK onp(ser9) GSK3 $\beta$ was demonstrated by labeling the cells with a pMEK specific antibody (red) and a p(ser9)GSK3 $\beta$ specific antibody (green). In figure 1 $\mathrm{g}$, there is an absence of pMEKin the centrosomal areas. Phospho(ser9) GSK3 $\beta$ (green) can be visualizedin the centrosomal areas in Figure 1h. Note the absence of yellow spots at the centrosomal areas that would otherwise indicate the co-localization between the two kinases in the merged image in Figure 1i (indicated by arrows). The inset in Figure 1i indicates a metaphase cell labeled with antibodies against $\gamma$-tubulin (green) at the centrosomes.In MEK siRNA treated cells, the effects of inhibiting MEK on pPKC $\zeta$ was demonstrated next by labeling the cells with a pMEK specific antibody (red) and a $\mathrm{pPKC} \zeta$ specific antibody (green). In Figure 1j, there is an absence of pMEK in the centrosomal areas. PhosphoPKC (green) can be visualized in the centrosomal areas in Figure 1k. Note the absence of yellow spots at the centrosomal areas in the merged image in Figure 11 (indicated by arrows).

MEK was also inhibited by a different method that is, using a pharmacological inhibitor of MEK to test if the same results were observed. Cells were treated with the pharmacological inhibitor against MEK, U0126 which has been shown to inhibit MEK1 and MEK2 by non-competitive inhibition (Duncia et al., 1998; Favata et al., 1998) and cells were treated with U0126. In the U0126 inhibitor treated cells, the effects of inhibiting MEK on p(ser9)GSK3 $\beta$ was assessed by labeling the cells with a pMEK specific antibody (red) and a p(ser9)GSK3 $\beta$ specific antibody (green). In Figure $1 \mathrm{~m}$, there is an absence of red pMEKin the centrosomal areas of the cell, while green $\mathrm{p}(\operatorname{ser} 9)$ GSK3 $\beta$ can be visualized in the centrosomal areas (Figure 1n). Aco-localization between the two kinases in the merged image in Figure 1o (indicated by arrows) is absent. The inset in Figure 1o indicates a metaphase cell showing $\gamma$-tubulin (green) at the centrosomes. In U0126 inhibitor treated cells, the effects of MEK inhibition on pPKC $\zeta$ was assessed next by labeling the cells with a pMEK specific antibody (red) and a pPKC $\zeta$ specific antibody (green). The inhibitor blocked pMEK (Figure $1 \mathrm{p}$ seen as an absence of red), but $\mathrm{pPKC} \zeta$ (green) is present and is shown in the merged image in Figure $1 \mathrm{r}$ (indicated by arrows).

\subsection{Effects of MEK Inhibition on Protein Expression}

A biochemical confirmation of the results from the immunocytochemical co-localization experiments in the previous section, shows the effect of MEK inhibition on cellular protein expression of pMEK, p(ser9)GSK3 $\beta$ and $\mathrm{pPKC} \zeta$ (Figure 2). Cell lysates were prepared from both the inhibitor treatments as well as the control cellsand then subjected to immunoblotting. All the blots in Figure 2 were also treated with an antibody against Myosin-1 (200kD molecular weight) as a loading control to correct for loading errors (see Materials and Methods). Cells treated with inhibitors of MEK activity were first assessed to determine the effects on total MEK (Figure 2a) and pMEK (Figure 2b). The signal for both of these was absent though clearly visible in control cells and also the DMSO carrier control. This was observed for both MEK siRNA and U0126 treated cells (Figures a-b).

Phospho(ser9)GSK3 $\beta$ antibody was used next to detect protein expression of $p(\operatorname{ser} 9)$ GSK3ßin the control lysate along with the U0126 and MEK siRNA treated lysates (Figure 2c). The expression of p(ser9)GSK3 $\beta$ was detected by a band at the $42 \mathrm{kD}$ molecular weight in the control lysate along with the U0126 and the MEK siRNA treated cell lysates. These results support the confocal microscopy images seen in Figures $1 \mathrm{~g}, \mathrm{~h}, \mathrm{i}, \mathrm{m}, \mathrm{n}$, and o where $\mathrm{p}(\mathrm{ser} 9) \mathrm{GSK} 3 \beta$ protein expression was not inhibited by MEK inhibitors, although there was a significant reduction in the total cellular protein levels of $\mathrm{p}(\operatorname{ser} 9)$ GSK3 $\beta$ after addition of the MEK inhibitors. This protein reduction is seen in the graphical representation of the average protein band intensity from the blots (Figure 2h). The band intensities for each blot were calculated as an average from three independent experiments and statistical significance was also calculated (see Materials and Methods).

In Figure $2 \mathrm{~d}, \mathrm{pPKC} \zeta$ antibody was used and $\mathrm{pPKC} \zeta$ expression was detected in the control lysate, also in the U0126 treated lysate and the MEK siRNA cell lysate as the $71 \mathrm{kD}$ molecular weight band. These results support the confocal microscopy images seen in Figures $1 \mathrm{j}, \mathrm{k}, 1, \mathrm{p}, \mathrm{q}$ and $\mathrm{r}$ where pPKC $\zeta$ protein expression was not inhibited by MEK inhibitors, although there was a significant reduction in the total cellular protein levels of $\mathrm{pPKC} \zeta$ as seen in Figure $2 \mathrm{~h}$.

To test the effects of MEK inhibition on the mitotic spindle microtubules, the protein levels of $\alpha$-tubulin were examined. In Figure 2e, the $\alpha$-tubulin antibody was used and $\alpha$-tubulin expression was detected in the control lysate, also in the U0126 treated lysate and the MEK siRNA cell lysate as a $55 \mathrm{kD}$ molecular weight band. There was a significant reduction in the total protein levels of $\alpha$-tubulin as seen in Figure $2 \mathrm{~h}$.

ERK is a known downstream target of MEK in the MAPK pathway of somatic cells (Pumiglia \& Decker, 1997; Zhang \& Liu, 2002; Orton et al., 2005; Shaul \& Seger, 2007; Borysova et al., 2008). The protein expression pattern of total ERK1/2 (tERK) in the cell population was examined next (Figure 2f). After immunoblotting, an 
antibody against tERK1/2 protein was used and the expression of tERK1/2 was visualized as two protein bands at the molecular weights of $44 \mathrm{kD}$ and $42 \mathrm{kD}$. The inhibitors, U0126 and MEK siRNA did not affect tERK1/2 protein levels since tERK1/2 was expressed in all of the treatments as seen in the blot and in the graph (Figure 2h). However when an antibody against phospho ERK1/2 (pERK1/2) was used to test the expression of the active phosphorylated form of ERK1/2 (Figure 2g), compared to the control cell lysate, pERK1/2 was not expressed in the U0126 and MEK siRNA treated cell lysates since the upstream effector pMEK was inhibited.
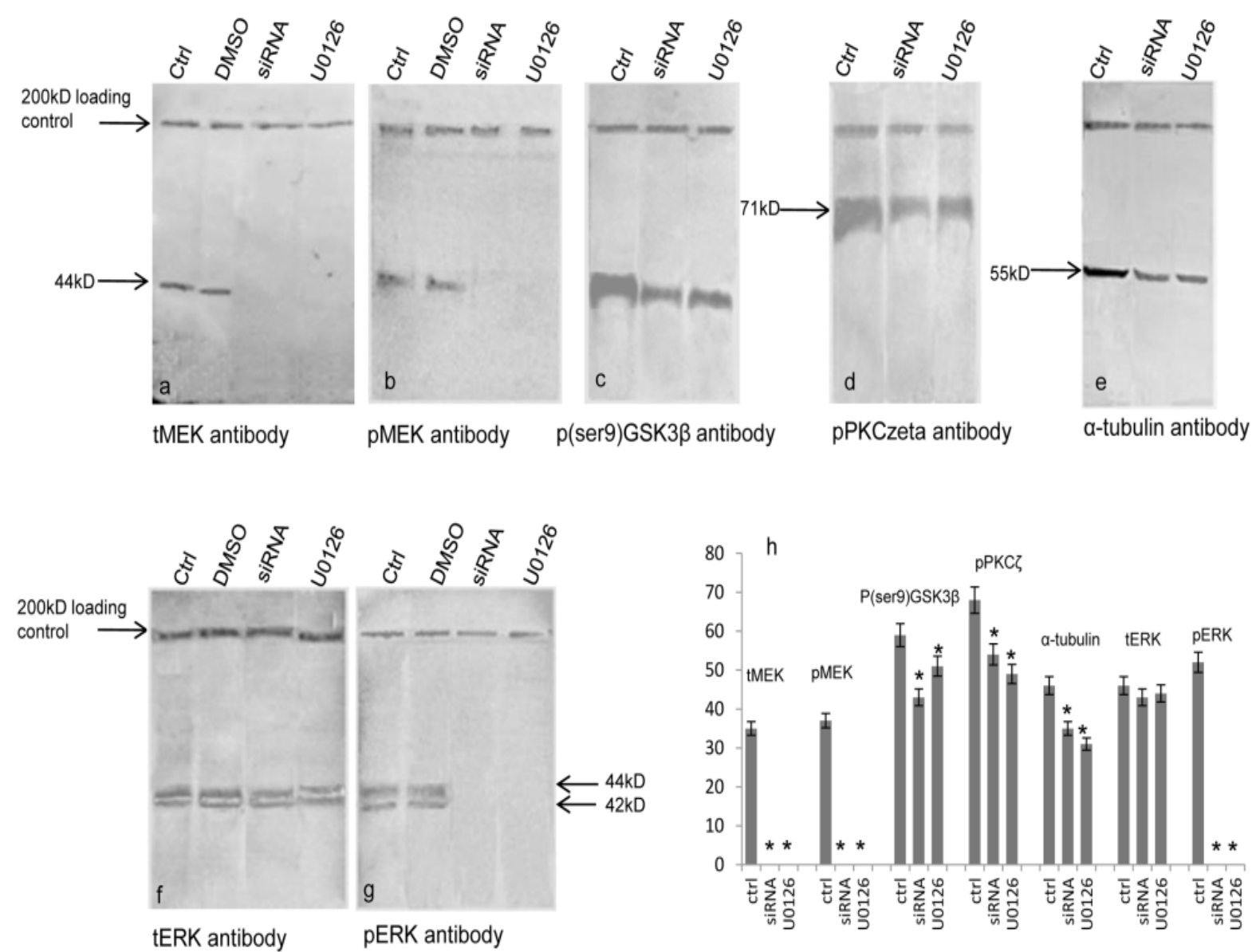

Kalive and Capco, Figure 2

Figure 2. Western analysis of MEK inhibited cell lysates

Control cells have been labeled 'ctrl' and 'DMSO' (for the carrier control) in all the blots of this figure. (a) An antibody to tMEK was used to detect tMEK protein in lysates from control cells, along with lysates from MEK siRNA treated cells and U0126 treated cells. Myosin-1 was used as the loading control with a molecular weight of $200 \mathrm{kD}$ in all the Western blots shown in this figure. (b) PhosphoMEK antibody was used to detect cellular protein levels of pMEK in control cells versus MEK siRNA treated cells and U0126 treated cells. Antibodies including (c) p(ser9)GSK3 $\beta$ antibody, (d) pPKC $\zeta$ antibody, (e) $\alpha$-tubulin antibody, (f) tERK antibody, and (g) pERK antibody were employed to detect the corresponding cellular protein levels in control cells versus MEK inhibited cells, inhibited by MEK siRNA and U0126. The histogram in (h) represents a quantification of the protein bands seen in the Western blots. The asterisks represent a significant difference from the control lysates. Experiments were performed in triplicate and statistical significance was calculated by a Student t-test and a probability of $\mathrm{p}<0.05$ was considered as significant. There is a slight reduction of $\mathrm{p}(\mathrm{ser} 9) \mathrm{GSK} 3 \beta$, $\mathrm{pPKC} \zeta$ and $\alpha$-tubulin protein levels. Equal amounts of each protein were loaded on the gels (see Materials and Methods). 


\subsection{Confirmation of MEKsiRNA Specificity; Effect of MEK Overexpression}

In order to confirm that MEK siRNA did inhibit the expression of MEK, experiments were performed with a MEK expression plasmid (Addgene plasmid repository, plasmid number: 21208: W1), a plasmid expressing the wild type form of MEK. In parallel experiments, 3T3 cells were subject to three treatments along with control cells with no treatment, 1) Cells that were treated with MEK siRNA alone, 2) cells that were transiently transfected with both MEK siRNA and MEK expression plasmid (MEKp), 3) Cells that were transiently transfected with MEKp alone (Figure 3). After 48hrs of treatment (see Materials and Methods for details), the total RNA from each of the treated cells along with control cells was isolated and the isolated RNA was subject to a Reverse Transcriptase-Polymerase Chain Reaction (RT-PCR) procedure where, the total isolated RNA from each treatment and control cells was transcribed to form the corresponding cDNA by an RT reaction, then the cDNA was amplified by a PCR reaction using the specific 5' and 3' DNA primers. The amplified cDNA was then subject to agarose gel electrophoresis (see Materials and Methods for details). Glyceraldehyde-6-phosphate dehydrogenase (GAPDH) expression was studied as a control since it is a known housekeeping gene and is often stably and constitutively expressed at high levels in most tissues and cells (Barber et al., 2005; Zainuddin et al., 2010). For each experimental sample the 5'-3' primers for GAPDH and MEK were used in order to amplify the corresponding cDNA.

In Figure 3a lane 2 was loaded with control cell cDNA amplified with MEK primers while lane 3 was loaded with control cell cDNA amplified with GAPDH primers. Lanes 2 and 3 indicate that MEK cDNA and GAPDH cDNA were present in control cells. In lanes 4, 5 the amplified cDNA from cells treated with MEK siRNA alone was loaded. MEK cDNA (using MEK primers) cannot be seen (lane 4) since its synthesis was inhibited by the siRNA, while GAPDH cDNA (using GAPDH primers) can still be seen (lane 5) similar to that seen in the control lane 3. In lanes 6, 7, the amplified cDNA from cells transfected with only MEKp was loaded. Both MEK cDNA (using MEK primers) and GAPDH cDNA (using GAPDH primers) can be seen similar to that seen in the control lanes 2 and 3. Lanes 1 and 10 in Figure 3a were loaded with a $1 \mathrm{~kb}$ DNA ladder.

Expression at the protein level, of these RT-PCR results was examined next by immunoblotting (Figures 3b, c). In parallel experiments, the cells were subject to the same treatments described in the above section along with control cells, and DMSO carrier treated cells. The total cell lysates were isolated and immunoblotting was then performed with the lysates. Antibodies against tMEK (Figure 3b) and against pMEK (Figure 3c) were used to visualize the protein expression of tMEK and pMEK. Total MEK (Figure 3b) was expressed from: a) Control cells that were not transfected; b) Cells that were transfected with both MEK siRNA and MEKp; c) Cells that were transfected with only MEKp. However, there was no expression of tMEK in the lane containing the lysate from cells transfected with only MEK siRNA compared to the expression in control cell lysates. This result was similar to the cDNA results in Figure 3a. Similar to the protein expression results of tMEK, Figure 3c indicates that pMEK was also expressed from: a) Control cells that were not transfected; b) Cells that were transfected with both MEK siRNA and MEKp; c) Cells that were transfected with only MEKp. However, there was no expression of pMEK in the lane containing the lysate from cells transfected with only MEK siRNA compared to the expression in control cell lysates.

The effects of overexpression of MEK on pMEK and $\alpha$-tubulin were studied next at the immunocytochemical level. Cells were subjected to three types of treatments along with the untreated controls in separate experiments. The three types of treatments include, transfection of cells with MEKp, treatment of cells with MEK siRNA alone, treatment of cells with a combination of MEK siRNA and MEKp. These three types of cell populations along with controls were labeled with pMEK antibodies (red). The cells treated with MEKp alone showed the presence of pMEK (Figure 3e) similar to the control cells (Figure 3d). The MEK siRNA treated cells showed the absence of an enrichment of pMEK (Figure 3h), while the cells treated with both MEK siRNA and MEKp showed an enrichment of pMEK. The three types of cell populations along with controls were labeled next with $\alpha$-tubulin antibodies (green). In MEKp treated cells the astral microtubules of the spindle are more pronounced (Figure 3g) compared to those in the control cells (Figure 3f). Compared to the MEK siRNA treated cell (Figure 3j) where the spindle microtubules are highly reduced in intensity, in cells treated with both MEK siRNA and MEKp the spindle microtubules are almost similar to the untreated control microtubules. 


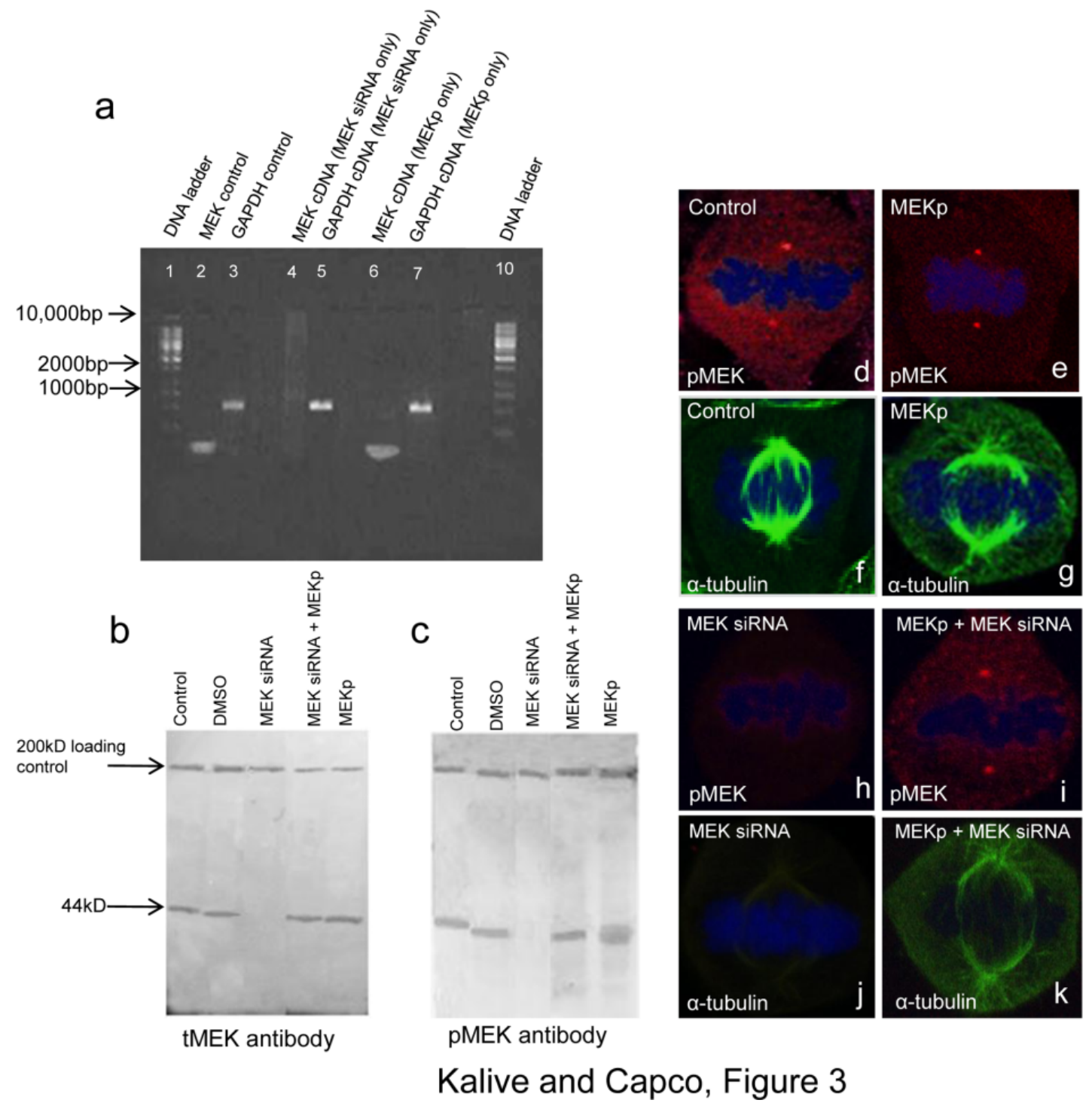

Figure 3. Confirmation of MEK siRNA specificity; Effect of MEK overexpression

(a) The PCR amplified cDNA was run on an agarose gel. The cDNA was processed by a reverse transcriptase reaction from cellular RNA. This RNA was isolated from cells treated with MEK siRNA alone, MEK plasmid alone (MEKp), a combination of MEK siRNA and MEK plasmid along with untreated control cells. For the PCR reaction, GAPDH primer set and MEK primer set were used. MEK cDNA can be visualized on the gel in MEKp treated cells, but not in MEK siRNA treated cells. (b) Western analysis of cell lysates from control cells, MEK siRNA treated cells, MEK siRNA and MEKp treated cells, and MEKp treated cells. An antibody to tMEK was used and tMEK protein bands can be detected in all the lanes except MEK siRNA treated cell lysate. (c) Western analysis of cell lysates from control cells, MEK siRNA treated cells, MEK siRNA and MEKp treated cells, and MEKp treated cells. An antibody to pMEK was used and pMEK protein bands can be detected in all the lanes except MEK siRNA treated cell lysate. Immunocytochemical analysis followed by confocal imaging was performed to study the effect of MEK overexpression on the enrichment of pMEK and $\alpha$-tubulin. (d) The enrichment of pMEK in a control cell versus (e) MEKp treated cell at the centrosomes is quite similar. However, compared to (f) the enrichment of $\alpha$-tubulin on the spindle in a control cell (g) the enrichment of $\alpha$-tubulin in a MEKp treated cell seems to show an increase in astral microtubules. Immunocytochemical analysis followed by confocal imaging was performed to study the effect of adding MEK siRNA along with MEKp on the enrichment of pMEK and $\alpha$-tubulin. (h) The absence of pMEK in a MEK siRNA treated cell can be compared to (i) where there was enrichment of pMEK when MEKp was added together with MEK siRNA. (j) The reduction in intensity of green $\alpha$-tubulin (part of the spindle microtubules) in MEK siRNA treated cell can be compared to (k) the spindle microtubules in a cell treated with both MEK siRNA and MEKp, where the spindle is similar to the spindle in a control cell. 


\subsection{Effects of MEK Inhibition on the Mitotic Spindle}

In order to assess the effects of inhibiting MEK on the mitotic spindle, cells were treated with MEK inhibitors in parallel experiments. An antibodyagainst $\alpha$-tubulin along with DRAQ5, was used to visualize the spindle microtubulesand chromosomes in three stages of mitosis, namely metaphase, anaphase, and telophase. In Figure $4 \mathrm{a}$, the metaphase mitotic spindle of a control cell ( $\alpha$-tubulin, green) is shown. An intact spindle apparatus at this stage with intact microtubules enveloping the chromosomes (blue) from both spindle pole regions can be visualized. However, in cells treated with MEK siRNA (Figure 4b) the metaphase spindle visualized by $\alpha$-tubulin (green) indicates areduction in brightness of microtubules compared to the control metaphase spindle in Figure 4a. In cells treated with U0126, the metaphase spindle visualized by $\alpha$-tubulin as green (Figure 4c) also indicates a reduction in the brightnessof microtubules compared to the control.In order to quantify this, the number of green pixels in the region of the spindle was quantified. One hundred cells were visualized at each stage of M-phase and agraphical representation of the spindle pixel intensity numbers at each M-phase stage is shown in Figure $4 \mathrm{j}$ for controls and each treatment. All the pixel intensity numbers in Figure $4 \mathrm{j}$ represent average pixel values of the entire spindle apparatus at each stage of the cell cycle. Statistical significance of these numbers was also calculated (see Materials and Methods section).

Anaphase stage in control cells visualized by $\alpha$-tubulin (green) demonstrates intact microtubules (Figure 4d) in a representative control cell. The MEKsiRNA treated cells indicate a reduction in pixel intensity (Figure 4j) of microtubules visualized by $\alpha$-tubulin antibody (green, Figure 4e) compared to the control (Figure 4d). Similarly in U0126 treated cells, the mitotic spindle in anaphase visualized by $\alpha$-tubulin (green, Figure 4f) indicates a reduction in the pixel intensity of microtubules (Figure 4j), compared to the control cell (Figure 4d).

Telophase stage in control cells (Figure 4g) demonstrates that themicrotubules are intact as visualized by $\alpha$-tubulin (green) at the spindle apparatus region. However, in MEKsiRNA treated cells (Figure 4h), the pixel intensity of microtubuleswas reduced (Figure 4j), visualized by $\alpha$-tubulin (green) compared to the control cell in Figure 4g. In the telophase stage of U0126 treated cells also (Figure 4i) there was a reduction in the pixel intensity of microtubules (Figure $4 \mathrm{j}$ ) visualized by the $\alpha$-tubulin antibody (green) compared to the control cell (Figure 4g). In any of these three stages, the size of the spindle in MEK inhibitor treated cells did not change (data not shown).

\subsection{Effect of MEK Inhibition on Number of Cells in Cell Division Stages}

Inhibition of MEK did not result in the disruption of the spindle though it did have the subtle effect of reducing the intensity of $\alpha$-tubulin in spindle microtubules. In order to test whether other subtle effects on mitosis occurred, progression through the cell cycle was assessed (Figure 4). In parallel experiments, cells were treated with MEK siRNA and U0126 inhibitors along with the untreated control cells. The percent cell population in interphase and in each stage of M-phaseincluding, pre-metaphase, metaphase, anaphase, telophase, and cytokinesis was examined by immunocytochemistry. The pre-metaphase stage encompassed all cells from early prophase through prometaphase. Spindle microtubules were identified by using antibodies against $\alpha$-tubulin(green), while the chromosomes were identified with DRAQ5. The number of control cells examined were 4244 where, $1 \%$ cells were in pre-metaphase stages, $1.5 \%$ cells were in metaphase, $0.6 \%$ cells were in anaphase, $0.4 \%$ cells were in telophase and $0.5 \%$ cells were in the cytokinesis stage (Figure $5 \mathrm{a}$ ). The absolute numbers of cells for each stage of M-phaseare indicated above the corresponding columns in Figure 5a. A total of $4 \%$ cells were in the mitotic phase while $96 \%$ (4092 cells) were in interphase stages of the cell cycle indicated by the pie chart in Figure 5a.

In MEK siRNAtreated cells (Figure 5b), 4172 cells were examined and the percent cells in each M-phase stage were significantly lower than the corresponding control cells. The absolute numbers of cells in each stage of M-phase are indicated above the corresponding columns in Figure $5 \mathrm{~b}$. A total of $1.25 \%$ cells were present in the mitotic phase while $98.75 \%$ (4111) cells were present in interphase stages of the cell cycle (pie chart in Figure $5 b)$.

In U0126 treated cells also (Figure 5c), 3975 cells were examined andthe percent cells in each M-phase stage were significantly lower than the corresponding control cells. The absolute numbers of cells in each stage of M-phase are indicated above the corresponding columns in Figure $5 \mathrm{c}$. A total of $1.5 \%$ cells were present in the mitotic phase while 98.5\% (3916) cells were present in interphase stages of the cell cycle (pie chart in Figure 5c). Statistical significance of these cell numbers from two treatments compared to the control cell numbers was calculated and a $p$-value of $p<0.05$ was considered significantly different in comparison to the control cells. The asterisks above the columns in the graph (Figure 5b) indicate significant difference from the control cells. 

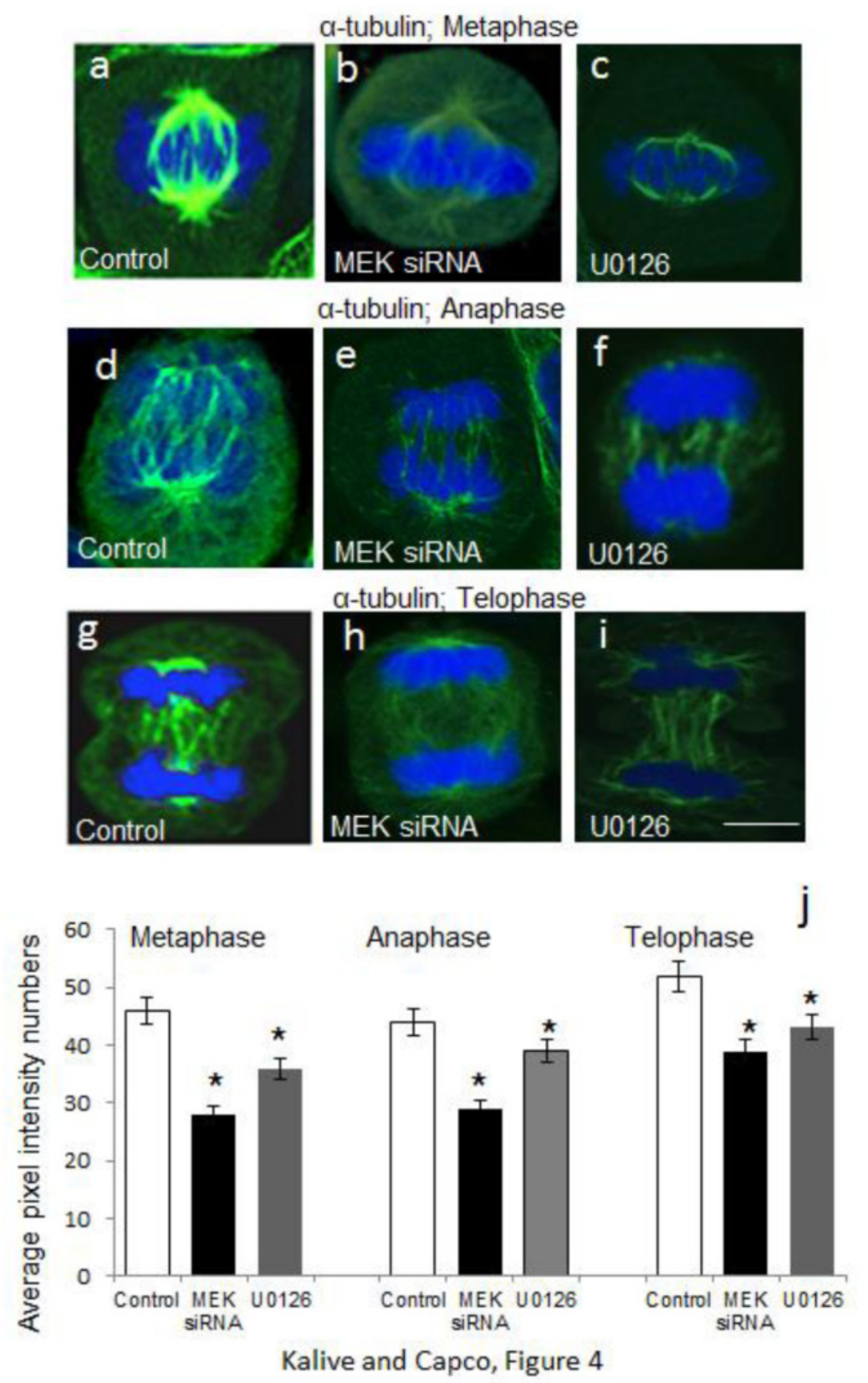

Figure 4. Effect of MEK inhibition on $\alpha$-tubulin

(a) A control cell at metaphase showing an intact mitotic spindle. (b) A MEK siRNA treated cell indicating a reduction in the green pixel intensity of spindle microtubules at metaphase. (c) A U0126 treated cell indicating a reduction in the green pixels of spindle at metaphase. (d, e, f) A control cell, a cell treated with MEK siRNA, and a cell treated with U0126 respectively indicating a reduction in green pixel intensity of the spindle at anaphase. (g, h, i) Control cell versus MEK siRNA treated cell and U0126 treated cell respectively at telophase indicating a pixel intensity reduction in MEK inhibited cells. (j) The pixel intensity values for metaphase, anaphase and telophase are indicated in the histogram. The asterisks represent a significant difference from the control pixel intensity values. Experiments were performed in triplicate and statistical significance was calculated by a Student t-test and a probability of $\mathrm{p}<0.05$ was considered as significant. 


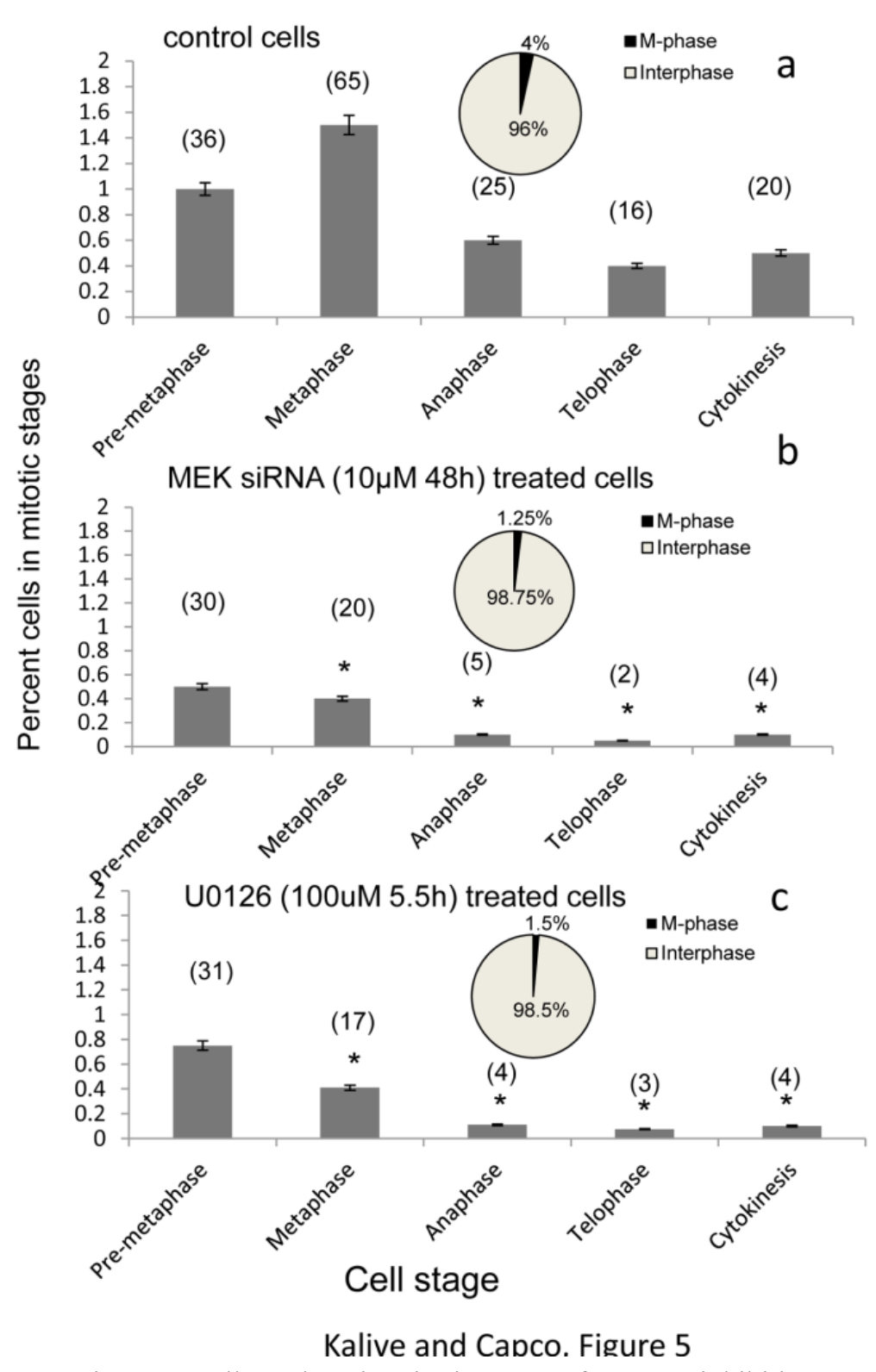

Figure 5. Cell numbers in mitotic stages after MEK inhibition

(a) The number of control cells in M-phase stages including, pre-metaphase (stages encompassing early prophase through prometaphase), metaphase, anaphase, telophase and cytokinesis are represented by a histogram. The pie chart inset in (a) indicates the percentage of cell in interphase versus M-phase. (b) The number of MEK siRNA treated cells in M-phase stages including, pre-metaphase (stages encompassing early prophase through prometaphase), metaphase, anaphase, telophase and cytokinesis are represented by a histogram. There is a significant reduction in the number of cells in M-phase stages compared to the control cell numbers which is indicated on the histogram by asterisks. (c) The number of U0126 treated cells in M-phase stages are represented by a histogram. A significant reduction in cell numbers compared to that of control cells is indicated by asterisks. Statistical significance was calculated by a Student t-test and a probability of $p<0.05$ was considered as significant. The pie chart insets in (b) and (c) represent the percent cells in interphase versus M-phase and there is an increase in interphase cells when MEK is inhibited.

\subsection{Effects of Inhibition of ERK Activation}

To test if the ERK activation inhibitor has effects similar to that of the MEK inhibitors, on the number of cells in M-phase versus interphase, the percent cells in each of the M-phase stage were studied. The ERK inhibitor used was a peptide inhibitor that prevents activation of ERK by pMEK. The enrichment of active ERK (pERK) was detected in control cells by a pERK antibody (red, Figure 6a), while in ERK inhibitor treated cells there is an 
absence of pERK (absence of red, Figure 6b). Figure 6c shows a graphical representation of the percentage of cells in each of the mitotic stages studied. In this graph, control cell percentages (shown as white columns in Figure 6a marked 'ctrl') were compared to the cells treated with the ERK1/2 peptide inhibitor (shown as black columns in Figure 6c marked 'exp'). The number of cells counted for this study was 4200. Compared to the control cell percentages, a significantly lesser percentage of ERK inhibitor treated cells were present in the pre-metaphase and metaphase stages. Also, none of the ERK inhibitor treated cells were present in anaphase, telophase or cytokinesis compared to the control cells. The absolute numbers are indicated above the corresponding columns in Figure $6 \mathrm{c}$.A total of $99.6 \%$ cells were present in interphase stageswhile $0.4 \%$ cells were present in M-phase (pie-chart in Figure 6c).
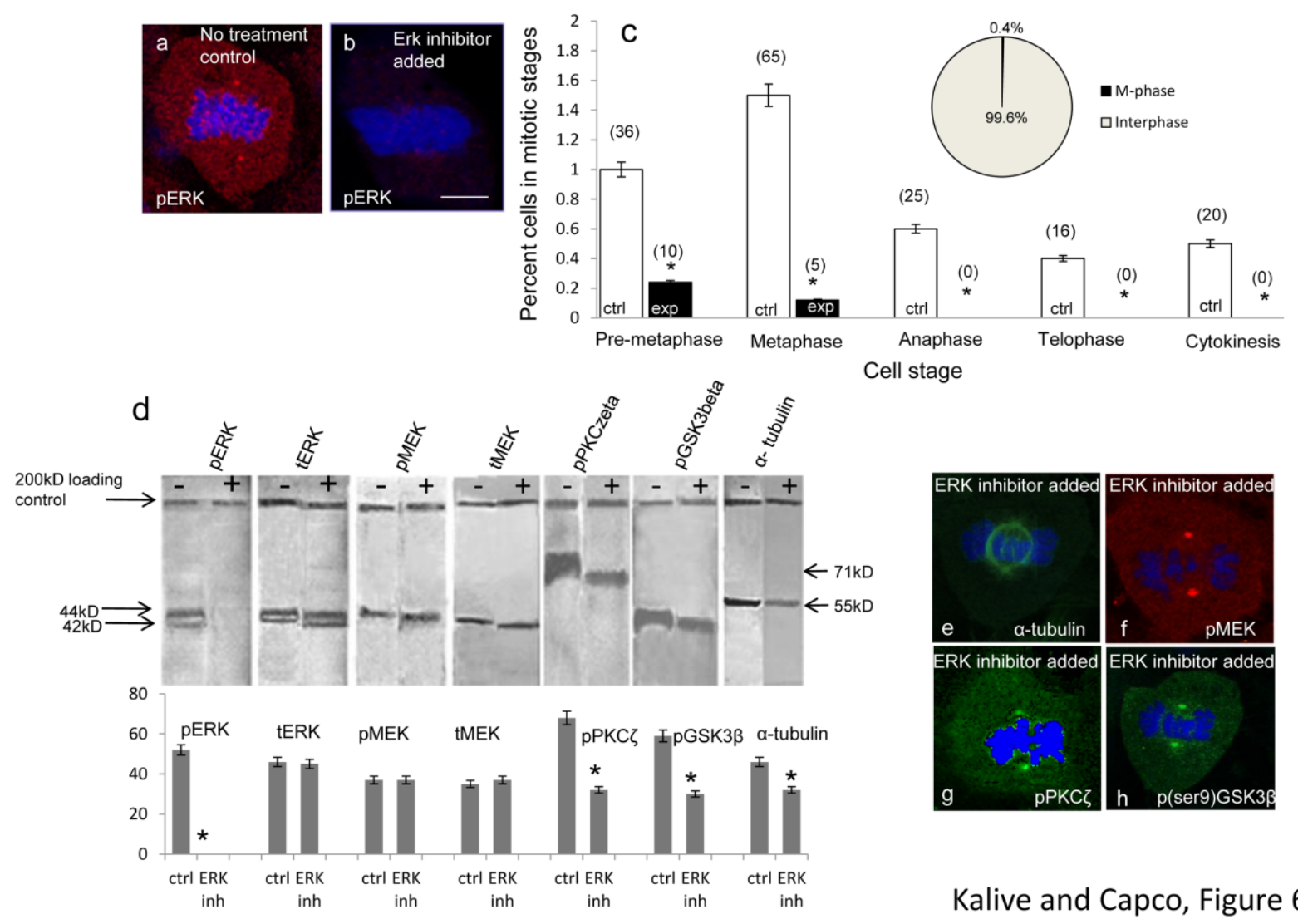

Figure 6. Effects of ERK activation peptide inhibitor

(a) pERK (red) exists at the centrosomes in control cells while (b) in ERK inhibitor treated cells there is an absence of pERK. (c) The number of control cells in M-phase (ctrl) versus the number of ERK inhibitor treated cells in M-phase (exp) are represented by a histogram. The M-phase stages that were counted include, pre-metaphase (stages encompassing early prophase through prometaphase), metaphase, anaphase, telophase and cytokinesis. In ERK inhibitor treated cells, no cells in anaphase, telophase and cytokinesis were identified. The pie chart inset in (c) indicates the percentage of cells in interphase versus M-phase. A significant reduction in cell numbers compared to that of control cells is indicated by asterisks. (d) Western analyses of control cell lysates (indicated by a '-'on the blot) versus ERK inhibitor treated cell lysates (indicated by a '+' on the blot).

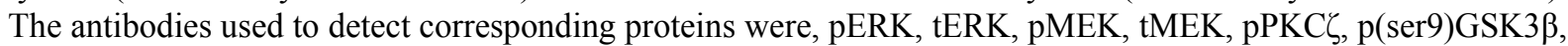
and $\alpha$-tubulin. The relative quantitation of these protein levels from the intensities of the protein bands is represented by a histogram below the western blots in (d). A significant reduction in band intensity compared to that of control cell lysates is indicated by asterisks. Statistical significance was calculated by a Student t-test and a probability of $\mathrm{p}<0.05$ was considered as significant. (e) Cells treated with the ERK inhibitor were tested immunocytochemically for the enrichment of $\alpha$-tubulin (green), (f) pMEK (red), (g) pPKC $($ green), and (h) $\mathrm{p}(\operatorname{ser} 9)$ GSK3 $\beta$. It can be seen that these kinases are not absent at the centrosomes. All experiments were performed in triplicate. 
The protein expression patterns in control cells compared toERK inhibited cells were examined next by immunoblottingusing the antibodies against the proteins indicated on the lanes (Figure 6d). The untreated control cell lysates are indicated by "." while ERK1/2 inhibitor treated cell lysates are indicated by "+" on the lanes in Figure 6d. In the control cell lysate lane, the band for pERKcan be visualized. In lane 3 of the blot, there is an absence of active pERK protein band, while lane 4 shows the presence of tERK ( $44 \mathrm{kD}$ and $42 \mathrm{kD}$ protein bands). The protein bands for pMEK and tMEK can be visualized in lanes 5 and 6 respectively in the inhibitor treated cell lysates. PhosphoPKC $\zeta$ can be visualized in lane 7 and p(ser9)GSK3 $\beta$ can be visualized in lane 8 of Figure $6 \mathrm{~d}$. Lane 9 shows the presence of $\alpha$-tubulin. A comparison of the relative intensities of each protein band in the blot is shown as a histogram below the blot. From the histogram in Figure $6 \mathrm{~d}$ it can be seen that the amounts of pPKC $\zeta, \mathrm{p}(\mathrm{ser} 9) \mathrm{GSK} 3 \beta$, and $\alpha$-tubulin proteins are significantly reduced in the ERK inhibitor added lysates compared to the control lysates.

ERK inhibited cells were labeled with an antibody against $\alpha$-tubulin (green) visualized along the mitotic spindlein Figure 6e. An antibody against pMEK (red) was visualized in the centrosome areas in Figure $6 \mathrm{f}$. An antibody against $\mathrm{pPKC} \zeta$ (green) was visualized in the centrosome areas in Figure $6 \mathrm{~g}$. The enrichment of $\mathrm{p}(\mathrm{ser} 9)$ GSK $3 \beta$ (green) in the centrosome areaswas visualized in Figure $6 \mathrm{~h}$. The enrichment of $\mathrm{pPKC} \zeta$ and $\mathrm{p}(\operatorname{ser} 9)$ GSK $3 \beta$ at the centrosome was not absent in ERK inhibitor treated cells although the enrichment of $\alpha$-tubulin along the mitotic spindle seems to have reduced compared to that in the MEK inhibited cells in Figure 4.

\section{Discussion}

This study demonstrates that pMEK, $\mathrm{pERK}, \mathrm{pPKC} \zeta$, and $\mathrm{p}(\mathrm{ser} 9) \mathrm{GSK} 3 \beta$ were all enriched at the centrosomes of the mitotic spindle in $3 \mathrm{~T} 3$ cells. Also, pPKC $\zeta$ and p(ser9)GSK3 $\beta$ each co-localized with pMEK and pERK at the centrosomes suggesting that these former two kinases may play an important role in mitotic spindle regulation. However inhibition of MEK by siRNA and by a chemical inhibitor indicated the following. 1) The enrichment of pPKC $\zeta$ or $\mathrm{p}(\operatorname{ser} 9) \mathrm{GSK} 3 \beta$ at the centrosomes was not inhibited, although there was a slight decrease in total cellular protein levels of $\mathrm{pPKC} \zeta$ and $\mathrm{p}(\mathrm{ser} 9) \mathrm{GSK} 3 \beta$. This suggested that these two kinases are not downstream targets of pMEK but may act either upstream of these kinases or alternatively may be in a separate pathway that engages in crosstalk with the MEK/ERK pathway.2) There was a significant decrease in pixel intensity of the spindle microtubules when MEK was inhibited and the $\alpha$-tubulin protein levels were also reduced. 3) The effect of MEK inhibition caused a slower progression of cells through M-phase compared to control cells. A peptide inhibitor that inhibited activation of ERK by pMEK was used and inhibition of pERK indicated the following. 1) The enrichment of pPKC $\zeta$ or p(ser9)GSK3 $\beta$ at the centrosomes was not inhibited, as seen when MEK was inhibited. 2) There was a decrease in the $\alpha$-tubulin protein levels and there was likely a decrease in the number of spindle microtubules. The number of spindle microtubules seemed to be further reduced thanwhat was seen when MEK was inhibited. 3) In contrast to what was seen when MEK was inhibited, inhibition of pERK caused an absence of cells in anaphase, telophase, and cytokinesis.

Thisstudy examined whether pMEK/pERKco-localizedwith pPKC $\zeta$ and/or with p(ser9)GSK3 $\beta$. Previously, the putative co-localization of these four kinases has not been examined in a single study. Separate studies have shown thatpMEK, $p E R K, p P K C \zeta$, and p(ser9)GSK3 $\beta$ are enriched at the centrosomes of the mitotic spindle (Lehrich \& Forrest, 1994; Shapiro et al., 1998; Willard \& Crouch, 2001; Etienne-Manneville \& Hall, 2003; Wakefield et al., 2003; Jope \& Johnson, 2004; Liu et al., 2006; Kalive et al., 2011; Collelo et al., 2012) but have not examined their interactions. Results from this study indicated that $\mathrm{p}(\operatorname{ser} 9) \mathrm{GSK} 3 \beta$ and $\mathrm{pPKC} \zeta$ are possibly involved in maintaining an intact mitotic spindle independent of the MEK/ERK pathway in mouse 3T3 fibroblasts, although earlier studies have indicated that $\mathrm{p}(\operatorname{ser} 9)$ GSK3 $\beta$ can act downstream of the MAPK pathway in other cells and is involved in maintaining the dynamic instability of microtubules (Goold et al. 1995; Goold et al., 1999; Scales et al., 2009). PKC $\zeta$ also has been implicated by other studies to be upstream of the MAPK pathway (Berra et al., 1995; Short et al., 2006). We speculated that these kinases may independently regulate specific components of the spindle since the absence of MEK/ERK activity and the presence of $\mathrm{p}(\mathrm{ser} 9) \mathrm{GSK} 3 \beta$ and $\mathrm{pPKC} \zeta$ at the centrosomes resulted in a partially intact spindle. Interestingly, in this study when MEK was overexpressed the astral microtubules seemed to have increased which suggested that MEK may also be involved in regulation of astral microtubules.Studies have shown microtubule associated proteins (MAPs) to be substrates of both ERK and GSK3 $\beta$, and performed specific functions to regulate microtubules (Goold et al., 1995; Scales et al., 2009). Other MAPs including MAP-1, MAP-2, MAP-4 have been shown to be substrates of ERK1/2 (Lin et al., 1993; Seger \& Krebbs, 1995; Zhang \& Liu, 2002) that are involved in nucleation and stabilization of microtubules (Sanchez et al., 2000). In the current study, the reduction in pixel intensity at the spindle suggested that the spindle may have fewer microtubules, if so,this reduced spindle number may be one 
reason for slow M-phase progression of MEK/ERK inhibited cells.Alternatively, other studies have shown that inhibition of MEK/ERK inhibits the phosphorylation of downstream cyclin dependent kinases (cdks) which in turn slows the progression of cells through M-phase (Pumiglia \& Decker, 1997; Willard \& Crouch, 2001; Horne \& Guadagno, 2003; Harding et al., 2003; Chambard et al., 2007).

Phospho(ser9)GSK3 $\beta$ has been shownto be involved in transport of centrosomal proteins to the centrosome by stabilizing the dynein complex, resulting in the regulation of a focused microtubule organization (Fumoto et al., 2006; Izumi et al., 2008). In addition, pPKC $\zeta$, has been shown to be important for microtubule-kinetochore attachment (Liu et al., 2006). In another study, ERK was shown to phosphorylate the kinetochore motor protein CENP-E on sites that regulate the interaction of centromere-binding protein E (CENP-E) with microtubules. ERK could play a role in mitotic progression by altering the ability of CENP-E to mediate the interactions between chromosomes and microtubules (Zecevic et al., 1998; Willard \& Crouch, 2001; Chambard et al., 2007). As an extension to these earlier studies, this study indicated that ERK inhibition did cause slower mitotic progression in $3 \mathrm{~T} 3$ cells possibly due to a reductionin the number of spindle microtubules. Since MEK/ERK, $\mathrm{p}(\mathrm{ser} 9) \mathrm{GSK} 3 \beta$, and $\mathrm{pPKC} \zeta$ seemed to regulate different parts of the mitotic spindle, absence of MEK/ERK alone is necessary but not indispensable for $3 \mathrm{~T} 3$ cells to maintain a spindle. A previous study showed abnormal spindles in the metaphase stage of U0126 treated cells (Guadagno \& Horne, 2003). Additionally, the current study indicated a significant decrease in pixel intensity of the spindle microtubules in U0126 treated and MEK siRNAtreated cells compared to control cells in metaphase, anaphase and telophase stages. Thus there was a reduction in total number of spindle microtubules in all these stages. Inhibition of MEK/ERK however, did not shorten or lengthen the microtubules in $3 \mathrm{~T} 3$ cells as observed in the currentstudy. The reduction in total cellular protein levels of $\alpha$-tubulin in MEK/ERK inhibited cells as demonstrated in the current study is a further confirmation of reduction in the number of spindle microtubules.

MEK/ERK, PKC , and p(ser9)GSK3 $\beta$ are kinases that are bound to scaffold proteins (Morrison \& Davis, 2003; Macara, 2004; Moscat et al., 2006; Sacks, 2006; Marks et al., 2009). Scaffold proteins are molecular sockets that bind several signal transducing proteins in such a way that the signaling interactions are facilitated and rendered more specific (Marks et al., 2009). These kinases seem to specifically regulate different elements of the spindle apparatus in 3T3 cells. The results from our study indicated that the MEK/ERK pathway may not have an important role in regulation of the centrosome in somatic cells, but it does have an important role in spindle microtubule regulation along with $\mathrm{p}(\mathrm{ser} 9) \mathrm{GSK} 3 \beta$ and $\mathrm{pPKC}$. The kinases, MEK, PKC $\zeta$ and GSK $3 \beta$ are probably not part of a single signaling pathway, but have overlapping functions in regard to preserving normal centrosomes and normal spindles. Phospho(ser9)GSK3 $\beta$ and PKC $\zeta$ may be involved in regulating the centrosome which is the microtubule organizing center of somatic cells (Compton, 2000; Debec et al., 2010; Walczak et al., 2010), both these kinases being part of an independent pathway. Alternatively, pPKC $\zeta$ could be upstream of the MEK/ERK pathway and also upstream to GSK3 $\beta$ in parallel to the MEK/ERK pathway, leading to the regulation of different elements of the mitotic spindle. These four kinases are important for normal cell division and inhibition of any one of these kinases can affect cell division dynamics.

\section{Conclusions}

The studies in this paper suggest that, 1) the two kinases, $\mathrm{pPKC} \zeta$ and $\mathrm{p}(\mathrm{ser} 9) \mathrm{GSK} 3 \beta$ are not downstream targets of pMEK but may act either upstream of pMEK and pERK or alternatively may be in a separate pathway that engages in crosstalk with the MEK/ERK pathway. 2) The effect of MEK inhibition causeda decrease in the $\alpha$-tubulin protein levels. This effect on the $\alpha$-tubulin protein levels possibly resulted in a slower progression of cells through M-phase compared to control cells. 3) The enrichment of pPKC $\zeta$ or p(ser9)GSK3 $\beta$ at the centrosomes was not inhibited, when MEK was inhibited. 4) The number of spindle microtubules seemed to be further reduced when ERK was inhibited than what was seen when MEK was inhibited. 5) In contrast to what was seen when MEK was inhibited, inhibition of pERK caused an absence of cells in anaphase, telophase, and cytokinesis.

\section{Acknowledgements}

We wish to thank the W. M. Keck Bioimaging Laboratory, and the Molecular Biology Laboratory at the School of Life Sciences, Arizona State University.

\section{References}

Berra, E., Díaz-Meco, M. T., Lozano, J., Frutos, S., Municio, M. M., Sánchez, P., ... Moscat, J. (1995). Evidence for a role of MEK and MAPK during signal transduction by protein kinase C zeta. EMBO J., 14, 6157-6163. Retrieved from http://www.ncbi.nlm.nih.gov/pubmed/8557035 
Borysova, M. K., Cui, Y., Snyder, M., \& Guadagno, T. M. (2008). Knockdown of B-Raf impairs spindle formation and the mitotic checkpoint in human somatic cells. Cell Cycle, 7, 2894-2901. Retrieved from http://www.ncbi.nlm.nih.gov/pubmed?term=borysova\%202008

Brändlin, I., Hübner, S., Eiseler, T., Martinez-Moya, M., Horschinek, A., Hausser, A., ... Johannes, F. J. (2002). Protein kinase C (PKC)eta-mediated PKC mu activation modulates ERK and JNK signal pathways. J. Biol. Chem., 277, 6490-6496. Retrieved from http://www.ncbi.nlm.nih.gov/pubmed/11741879

Burbank, K. S., Mitchison, T. J., \& Fisher, D. S. (2007). Slide-and-cluster models for spindle assembly. Curr. Biol., 17, 1373-83. Retrieved from http://www.ncbi.nlm.nih.gov/pubmed/17702580

Chambard, J. C., Lefloch, R., Pouysségur, J., \& Lenormand, P. (2007). ERK implication in cell cycle regulation. Biochim Biophys Acta, 8, 1299-1310.

Chang, S. J., Tzeng, C. R., Lee, Y. H., \& Tai, C. J. (2008). Extracellular ATP activates the PLC/PKC/ERK signaling pathway through the $\mathrm{P} 2 \mathrm{Y} 2$ purinergic receptor leading to the induction of early growth response 1 expression and the inhibition of viability in human endometrial stromal cells. Cell Signal, 20, 1248-1255.

Colello, D., Mathew, S., Ward, R., Pumiglia, K., \& LaFlamme, S. E. (2012). Integrins regulate microtubule nucleating activity of centrosome through mitogen-activated protein kinase/extracellular signal-regulated kinase kinase/extracellular signal-regulated kinase (MEK/ERK) signaling. J. Biol. Chem., 287, 2520-2530. Retrieved from http://www.ncbi.nlm.nih.gov/pubmed/22117069

Compton, D. A. (2000). Spindle assembly in animal cells. Annu. Rev. Biochem., 69, 95-114.

Corbit, K. C., Trakul, N., Eves, E. M., Diaz, B., Marshall, M., \& Rosner, M. R. (2003). Activation of Raf-1 signaling by protein kinase $\mathrm{C}$ through a mechanism involving Raf kinase inhibitory protein. J. Biol. Chem., 278, 13061-13068. Retrieved from http://www.ncbi.nlm.nih.gov/pubmed/12551925

Debec, A., Sullivan, W., \& Bettencourt-Dias, M. (2010). Centrioles: active players or passengers during mitosis. Cell Mol. Life Sci., 67, 2173-2194.

Duncia, J. V., Santella, J. B., Higley, C. A., Pitts, W. J., Wityak, J, Frietze, W. E., ... Olson, R. E. (1998). MEK inhibitors: the chemistry and biological activity of U0126, its analogs, and cyclization products. Bioorg Med. Chem. Lett., 8, 2839-2844. Retrieved from http://www.ncbi.nlm.nih.gov/pubmed/9873633

Etienne-Manneville, S., \& Hall, A. (2003). Cdc42 regulates GSK-3 $\beta$ and adenomatous polyposis coli to control cell polarity. Nature, 421, 753-756.

Favata, M. F., Horiuchi, K. Y., Manos, E. J., Daulerio, A. J., Stradley, D. A., Feeser, W. S., ... Trzaskos, J. M. (1998). Identification of a novel inhibitor of mitogen-activated protein kinase kinase. J. Biol. Chem., 273, 18623-18632.

Frame, S., \& Cohen, P. (2001). GSK3 takes centre stage more than 20 years after its discovery. Biochem. J. 359, $1-16$.

Fumoto, K., Hoogenraad, C. C., \& Kikuchi, A. (2006). GSK-3beta-regulated interaction of BICD with dynein is involved in microtubule anchorage at centrosome. EMBO J., 25, 5670-5682.

Goold, R. G., \& Gordon-Weeks, P. R. (2005). Glycogen synthase kinase 3beta and the regulation of axon growth.Biochem. Soc. Trans., 32, 809-811.

Goold, R. G., Owen, R., \& Gordon-Weeks, P. R. (1999). Glycogen synthase kinase $3 \beta$ phosphorylation of microtubule-associated protein 1B regulates the stability of microtubules in growth cones. J. Cell Sci., 112, 3373-3384.

Guadagno, T. M., \& Ferrell, J. E Jr. (1998). Requirement for MAPK activation for normal mitotic progression in Xenopus egg extracts. Science, 282, 1312-1315. Retrieved from http://www.ncbi.nlm.nih.gov/pubmed/9812894

Habermann, L. (2012). New insights into subcomplex assembly and modifications of centrosomal proteins. Cell Div., 7, 17. Retrieved from http://www.ncbi.nlm.nih.gov/pubmed/22800182

Harding, A., Giles, N., Burgess, A., Hancock, J. F., \& Gabrielli, B. G. (2003). Mechanism of mitosis-specific activation of MEK1. J. Biol. Chem., 278, 16747-16754.

Hayne, C., Tzivion, G., \& Luo, Z. (2000). Raf-1/MEK/MAPK pathway is necessary for the G2/M transition induced by nocodazole. J. Biol. Chem., 275, 31876-31882. Retrieved from http://www.ncbi.nlm.nih.gov/pubmed/10884385 
Izumi, N., Fumoto, K., Izumi, S., \& Kikuchi, A. (2008). GSK-3beta regulates proper mitotic spindle formation in cooperation with a component of the gamma-tubulin ring complex, GCP5. J. Biol. Chem., 283, 12981-12991.

Jope, R. S., \& Johnson, G. V. W. (2004). The glamour and gloom of glycogen synthase kinase-3. Trends. Biochem. Sci., 29, 95-102.

Kalive, M., Baluch, D. P., \& Capco, D. G. (2012). Involvement of PKC $\zeta$ and GSK3 $\beta$ in the stability of the metaphase spindle. In Vitro Cell Dev. Biol. Anim., 2, 97-111.

Kholodenko, B. N. (2006). Cell-signalling dynamics in time and space. Nat Rev Mol Cell Biol., 3, 165-176. http://www.ncbi.nlm.nih.gov/pubmed/16482094

Lehrich, R.W., \& Forrest, J. N. Jr. (1994). Protein kinase C zeta is associated with the mitotic apparatus in primary cell cultures of the shark rectal gland. J. Biol. Chem., 51, 32446-32450.

Lin, L. L., Wartmann, M., Lin, A. Y., Knopf, J. L., Seth, A., \& Davis, R. J. (1993). cPLA2 is phosphorylated and activated by MAP kinase. Cell, 72, 269-278.

Liu, X. F., Xie, X., \& Miki, T. (2006). Inhibition of protein kinase C zeta blocks the attachment of stable microtubules to kinetochores leading to abnormal chromosome alignment. Cell Signal, 18, 2314-2323.

Macara, I. G. (2004). Parsing the polarity code. Nat Rev Mol Cell Biol., 5, 220-231.

Marks, F., Klingmuller, U., \& Muller-Decker, K. (2009). Cellular signal processing: An introduction to the molecular mechanisms of signal transduction. Garland Science, Taylor and Francis group, LLC., NY USA.

McIntosh, J., \& Landis, S. C. (1971). The distribution of spindle microtubules during mitosis in cultured human $\begin{array}{llllll}\text { cells. } & \text { J. } & \text { Cell. } & \text { Biol., } & \text { 49, 468-497. } & \text { Retrieved }\end{array}$ http://www.ncbi.nlm.nih.gov/pmc/articles/PMC2108320/?tool=pmcentrez

Morrison, D. K., \& Davis, R. J. (2003). Regulation of MAP kinase signaling modules by scaffold proteins in mammals. Annu Rev Cell Dev Biol., 19, 91-118. Retrieved from http://www.ncbi.nlm.nih.gov/pubmed/14570565

Moscat, J, Diaz-Meco, M. T, \& Wooten, M. W. (2006). Signal integration and diversification through the p62 scaffold protein. Trends Biochem Sci., 32, 95-100.

Nigg, E. (2001). Mitotic kinases as regulators of cell division and its checkpoints. Nature reviews, 2, 21-32.

Orton, R., Sturm, O. E., Vyshemirsky, V., Calder, M., Gilbert, D. R., \& Kolch, W. (2005). Computational modelling of the receptor-tyrosine-kinase-activated MAPK pathway. Biochem. J., 392, 249-261.

Puente, L. G., He, J. S., \& Ostergaard, H. L. (2006). A novel PKC regulates ERK activation and degranulation of cytotoxic T lymphocytes: Plasticity in PKC regulation of ERK. Eur. J. Immunol., 4, 1009-1018. Retrieved from http://www.ncbi.nlm.nih.gov/pubmed/16552708

Pumiglia, K. M., \& Decker, S. J. (1997). Cell cycle arrest mediated by the MEK/mitogen-activated protein kinase pathway. Proc Natl Acad Sci., 94, 448-452.

Roberts, E. C., Shapiro, P. S., Nahreini, T. S., Pages, G., Pouyssegur, J., \& Ahn, N. G. (2002). Mol. Cell. Biol., $22,7226-7241$.

Rozengurt, E. (2007). Mitogenic Signaling Pathways Induced by G Protein-Coupled Receptors. J. Cell. Physiol., 213, 589-602.

Sacks, D. B. (2006). The role of scaffold proteins in MEK/ERK signalling.Biochem Soc Trans., 34, 833-836. Retrieved from http://www.ncbi.nlm.nih.gov/pubmed/17052209

Saffery, R., Irvine, D. V., Griffiths, B., Kalitsis, P., \& Choo, K. H. (2000). Components of the human spindle checkpoint control mechanism localize specifically to the active centromere on dicentric chromosomes. Hum Genet., 107, 376-384.

Sánchez, C., Díaz-Nido, J., \& Avila, J. (2000). Phosphorylation of microtubule-associated protein 2 (MAP2) and its relevance for the regulation of the neuronal cytoskeleton function. Prog Neurobiol., 61, 133-168.

Scales, T. M., Lin, S., Kraus, M., Goold, R. G., \& Gordon-Weeks, P. R. (2009). Nonprimed and DYRK1A-primed GSK3 beta-phosphorylation sites on MAP1B regulate microtubule dynamics in growing axons. J. Cell Sci., $122,2424-2435$. 
Schmid-Alliana, A., Menou, L., Manié, S., Schmid-Antomarchi, H., Millet, M. A., Giuriato, S., ... Rossi B. (1998). Microtubule integrity regulates src-like and extracellular signal-regulated kinase activities in human pro-monocytic cells. Importance for interleukin-1 production. J. Biol. Chem., 273, 3394-3400.

Schmidt, S., Essmann, F., Cirtea, I. C., Kuck, F., Thakur, H. C., Singh, M., ... Piekorz, R. P. (2010). The centrosome and mitotic spindle apparatus in cancer and senescence. Cell Cycle., 9, 4469-4473.

Schonwasser, D., Marais, R. M., \& Marshall, C. J. (1998). Activation of the Mitogen-activated protein kinase/extracellular signal-regulated kinase pathway by conventional, novel and atypical protein kinase $\mathrm{C}$ isotypes. Mol Cell Biol., 18, 790-798.

Seger, R., \& Krebs, E. G. (1995). The MAPK signaling cascade. FASEB J., 9, 726-735. Retrieved from http://www.ncbi.nlm.nih.gov/pubmed/7601337

Shapiro, P. S., Vaisberg, E., Hunt, A. J., Tolwinski, N. S., Whalen, A. M., McIntosh, J. R., \& Ahn, N. G. (1998). Activation of the MKK/ERK pathway during somatic cell mitosis. J. Cell Biol., 142, 1533-1545.

Shaul, Y. D., \& Seger, R. (2007). The MEK/ERK cascade: from signaling specificity to diverse functions. Biochim Biophys Acta., 1773, 1213-26.

Short, M. D., Fox, S. M., Lam, C. F., Stenmark, K. R., \& Das, M. (2006). Protein kinase Czeta attenuates hypoxia-induced proliferation of fibroblasts by regulating MAP kinase phosphatase-1 expression. Mol. Biol. Cell, 4, 1995-2008. Retrieved from http://www.ncbi.nlm.nih.gov/pubmed/16467381

Towbin, H., Staehelin, T., \& Gordon, J. (1979). Electrophoretic transfer of proteins from polyacrylamide gels to nitrocellulose sheets: procedure and some applications. Biotechnology, 24, 145-149.

Wakefield, J. G., Stephens, D. J., \& Tavare, J. M. (2002). A role for glycogen synthase kinase-3 in mitotic spindle dynamics and chromosome alignment. J. Cell Sci., 116, 673-646.

Walczak C. E., Cai S., \& Khodjakov A. (2010). Mechanisms of chromosome behavior during mitosis. Nat. Rev. Mol. Cell Biol., 11, 91-102.

Walczak, C. E., \& Heald, R. (2008). Mechanisms of Mitotic Spindle Assembly and Function.Int. Rev. Cyt., 265, 111-158.

Walsh, S., Margolis, S. S., \& Kornbluth, S. (2003). Phosphorylation of the cyclin b1 cytoplasmic retention sequence by mitogen-activated protein kinase and Plx. Mol. Cancer Res., 4, 280-289. Retrieved from http://www.ncbi.nlm.nih.gov/pubmed/12612056

Willard, F. S., \& Crouch, M. F. (2001). MEK, ERK, and p90RSK are present on mitotic tubulin in Swiss 3T3 cells: a role for the MAP kinase pathway in regulating mitotic exit. Cell Signal, 9, 653-664. Retrieved from http://www.ncbi.nlm.nih.gov/pubmed/11495723

Wright, J. H., Munar, E., Jameson, D. R., Andreassen, P. R., Margolis, R. L., Seger, R., \& Krebs, E. G. (1999). Mitogen-activated protein kinase kinase activity is required for the $G(2) / M$ transition of the cell cycle in mammalian fibroblasts. Proc. Natl. Acad. Sci., 96, 11335-11340.

Yung, Y., Dolginov, Y., Yao, Z., Rubinfeld, H., Michael, D., Hanoch, T., ... Seger, R. (1997). Detection of ERK activation by a novel monoclonal antibody. FEBS Lett., 408, 292-296.

Zecevic, M., Catling, A. D., Eblen, S. T., Renzi, L., Hittle, J. C., Yen, T. J., ... Weber, M. J. (1998). Active MAP kinase in mitosis: localization at kinetochores and association with the motor protein CENP-E. J. Cell Biol., $142,1547-1558$.

Zhang, W., \& Liu, H. T. (2002). MAPK signal pathways in the regulation of cell proliferation in mammalian cells. Cell Res., 1, 9-18. Retrieved from http://www.ncbi.nlm.nih.gov/pubmed/11942415 